\title{
Theoretical research on kinematic and constructive parameters of roller presses for sweet sorghum
}

\author{
Mihai Olan ${ }^{1 *}$, Gheorghe Matei ${ }^{2}$, Livia Apostol ${ }^{3}$, Vasile Jinga ${ }^{4}$, Steluţa Lipianu ${ }^{4,5}$, Paul \\ Găgeanu ${ }^{1}$, Ana Zaica $^{1}$, Iulian Voicea ${ }^{1}$ and Oana Cristea $^{1}$ \\ ${ }^{1}$ INMA Bucharest, Romania \\ ${ }^{2}$ University of Craiova, Romania \\ ${ }^{3}$ IBA Bucharest, Romania \\ ${ }^{4}$ ICDPP Bucharest, Romania \\ ${ }^{5}$ USAMV Bucharest, Romania
}

\begin{abstract}
The overall objective of the project is to develop an eco-innovative system for pressing sweet sorghum by the generalised object method specific to the technical creation applied in this field. (Vitalie Belouasov). The representative technical solutions of the companies recognised in this field are known and it is necessary to use a creativity method to analyze the existing solutions, to assess technical and economic characteristics by methods specific to value analysis but also to find new constructive variants and choose the optimal variant that will then be developed by the design-research activity for the realisation of the technical documentation for the execution of an industrial prototype. The generalized object of the technical creation is in the form of a cylindrical morphological matrix, each sector representing a solution (sector represented by a triple assembly $\mathrm{BiCjDk}$, the total number of solutions being: $\mathrm{N}=\mathrm{i} \cdot \mathrm{j} \cdot \mathrm{k}$ solutions, some of which are known, others unknown. The incompatible ones must be eliminated, while the others must be analyzed, as they can lead to particularly efficient constructions after their complete solving.
\end{abstract}

\section{Introduction}

Because of the energy crisis by lowering oil resources and of air pollution, research has been made to find safe substitutes. Of these, the bioethanol produced from sweet sorghum is of special interest in this field, [1]. There is a large amount of sugar in sweet sorghum stem juice, [2]. The sweet sorghum stem juice is rich in fermenting sugar and is a desirable material for alcoholic fermentation, [3].

Based on the analysis of the existing technologies and equipment for juice extraction from the sweet plant stems, the opportunity to use roller presses for squeezing the juice from sweet sorghum stems is argued and the basic parameters of the press, which would ensure the obtaining of large quantities of raw sweet sorghum juice used to make monatomic alcohols and other products, are presented, [4;5].

\footnotetext{
*PhD. Mihai Olan: vibrobloc@yahoo.com
} 
The achievement of an optimal productivity related to the electric energy consumed in the case of pressing the sweet sorghum stems is determined by the kinematic study of the working parts' operating systems and can be obtained by analysing and optimizing the parameters that determine this technological process, [6].

By analysing the forces that act on the pressed material and determining the power consumed when pressing the material between the rollers, the energy consumed per unit time and the resulting productivity are obtained.

We will also analyse the variation of the working capacity depending on the thickness of the raw material layer the roller press is fed with and the rollers angular speed, but also the power variation of the driving electric motor according to the force required for driving the rollers, [7].

In the paper, the kinematic analysis of the roller press driving components is made, [8;9]

\section{Materials and methods}

\subsection{Theoretical presentation of sorghum stems entrainment between two rollers}

To obtain juice from sweet sorghum stems, we chose the press with three rollers having equal diameters and rotational speeds. In this case, the thickness of the raw material layer, denoted by $\mathrm{h}$, is pressed at thickness $\mathrm{s} 1$ at the primary passage between the upper roller and the primary pressing and entraining roller and then reaches thickness 2 at the final pressing between the first roller and the last roller, thicknesses given by the distances between rollers.

According to the literature we will notice that the forces with which the rollers act on the layer of stems for each zone are directed perpendicularly to the contact surface and can be reduced to a resultant force P. Decomposing this force in two perpendicular directions, namely of material compression and of material movement, we obtain the components Py that compresses the material and Px that pushes the material from the passage. At the same time, friction forces, which are applied tangentially to the rollers surface, act on the material, forces that can be presented by resultant $\mathrm{F}$. We will decompose the resultant force $\mathrm{F}$ and obtain the components Fx, which entrains the material between the rollers and Fy, which contributes to the pressing of the material. Fig.1, [3]

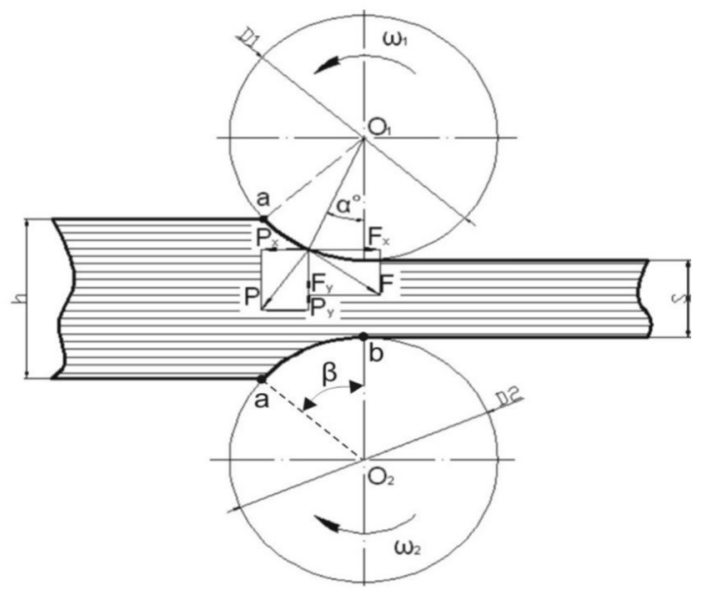

Fig. 1. Theoretical presentation of forces that arise in the pressing process, [2; 4]. 


\subsection{Analysis of sorghum stems entrainment between three rollers}

To extract juice from sweet plant stems, the most commonly used system is built in the three-roller version with equal diameters and rotational speeds and with a high degree of extraction.

Figure 2 shows the scheme of this pressing method. The raw material layer, with the initial thickness $h=30 \ldots 40 \mathrm{~mm}$, is pressed in two technological phases up to a final thickness of $s=5 \ldots 7 \mathrm{~mm}$, equal to the value of the passage between the rollers.

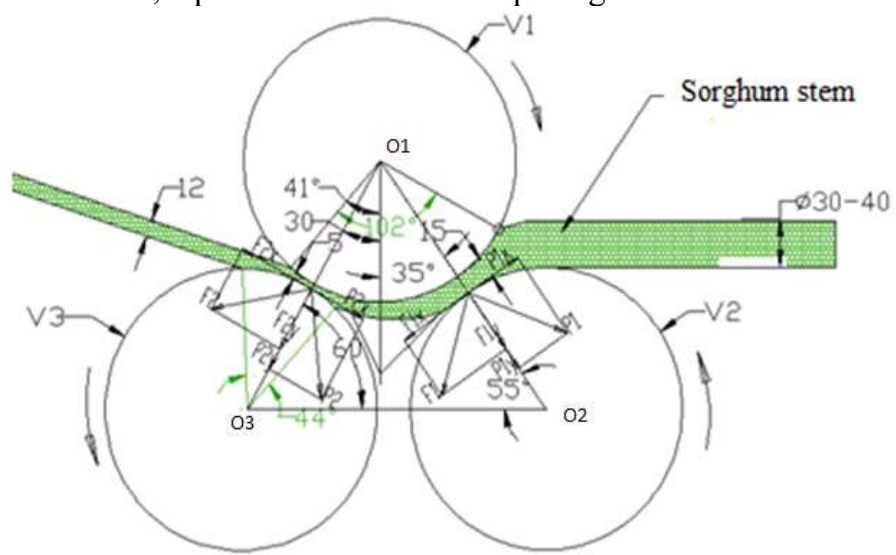

Fig.2. Scheme of forces application to the pressed material in the case of the three-roller press.

According to [1], the forces with which the rollers act on the layer of stems for each zone are directed perpendicularly to the contact surface and can be reduced to a resultant force $\mathrm{P}$ which will consist of the summing of the two forces P1 and P2 projected vertically in the contact area of each pair of drums. If we decompose these forces in two perpendicular directions, namely of material compression and of material movement, we obtain the components P1y; P2y (compressing the material) and P1x; P2x (pushing the material from the passage). At the same time, friction forces, which are applied tangentially to the rollers surface, act on the material, forces that can be presented by resultant $\mathbf{F 1}$ and F2.

By decomposing the resultant force $\mathbf{F 1}$ and F2, we obtain the components F1x respectively $\mathbf{F 2 x}$ which entrain the material between the rollers and $\mathbf{F 1 y}$ respectively $\mathbf{F} 2 \mathbf{Y}$ which contribute to the pressing of the material.

By analysing the pressing process we will find that when the rollers get nearer simultaneously with the decrease of space $s$, the contact angle $\alpha$ increases (if thickness $\mathbf{h}=$ const. $=30 \mathrm{~mm}$ ) and the application point of forces $\mathbf{P 1}$ and $\mathbf{P 2}$ moves away from the centreline $\mathrm{O}_{1} \mathrm{O}_{3}$ and $\mathrm{O}_{2} \mathrm{O}_{3}$.

This leads to the increase of the components P1x, P2x from the value P1y, P2y. When forces P1x and P2x exceed the friction forces component $\mathbf{F 1 x}$ respectivelyF $2 x$, the roller sliding begins and material movement stops. [1]

As it results from the above, the condition of entraining the material between the rollers is:

$$
F x \geq P x \text { or } F \cos \alpha \geq P \sin \alpha, \text { results } P \operatorname{tg} \varphi \cos \alpha \geq P \sin \alpha,
$$

For the application shown in Figure 2, respectively:

$$
F \cos 30^{\circ} \geq P \sin 30^{\circ}
$$


We'll have:

$$
F x 0.866 \geq P x 0.5 \text {, so } F \geq 1.73 P
$$

It can be seen that the thickness $h$ and the compression degree $\Delta_{h}$ of the entrained layer, for pressing between two rollers, depend on the rollers diameter $D$ and the friction coefficient $(f=\operatorname{tg} \varphi)$ of the material on the roller surface. Therefore, the increase in diameter $D$ and the friction coefficient $\operatorname{tg} \varphi$ increases the values of the layer thickness $h$ and its thinning $\Delta_{h}$, which improves the conditions of entraining the stem layer and increases the productivity of the pressing process $Q$ and juice squeezing degree $G E$.

\subsection{Productivity and liquid extraction degree when pressing the material between 3 rollers for the application shown in Figure 2}

The volume of material passing, in a unit of time, through a passage between two rollers having equal peripheral speed, considering that sliding is missing, is determined from the relation:

$$
V=b \cdot h \cdot v
$$

where: $b$ is the length of the roller (width of the pressing area) measured in mm;

$h$ - thickness of the layer entrained between rollers measured in $\mathrm{mm}$;

$v$ - peripheral speed of the rollers, measured in $\mathrm{m} / \mathrm{s}$.[3]

The mass of the material processed in a unit of time (productivity) can be determined, knowing the bulk density (volumetric mass) $\varphi$ of the material $\left(\mathrm{kg} / \mathrm{m}^{3}\right)$ :

$$
Q_{m v}=V \varphi=b \cdot h \cdot \varphi \cdot \delta
$$

We will notice that the material layer compresses from the initial thickness $h$ (max.40 $\mathrm{mm})$ to the final thickness $s(6 \ldots 7 \mathrm{~mm}$, passage value) when the material passes through the rollers. Following the compression process, the release of the liquid from the material is obtained and the increase of the squeezed material volumetric mass.

If the final distance exceeds $15 \mathrm{~mm}$, conditions are created for uneven pressing of the raw material layer: the larger diameter stems are pressed harder than those with a smaller diameter. In turn, the increase in force $P$ reduces stem pressing unevenness, however, providing maximum values in the case of the distance within the limits of $6 \ldots 7 \mathrm{~mm}$.

It is observed that the pressure increase significantly rises the compression coefficient of the vegetal mass:

$$
K=\gamma \cdot b / m
$$

and is the ratio between the volumetric mass of bagasse and of raw material respectively.

\subsection{Determining the power consumed when pressing the material between rollers}

When pressing the material, it is necessary not only to achieve press operation with safe stem entraining, high productivity and high juice extraction (squeezing) degree, but also minimal energy consumption.

As mentioned before, it is necessary to act on the material with a force $\mathbf{P}$ normal to the contact surface to ensure that the stems are entrained and pressed by the rollers. In order to operate the rollers with speed according to [1], a moment of torsion is required: 


$$
M_{t}=2 P \cdot ¥ \cdot l
$$

Where: $¥$ is the boom coefficient;

$\boldsymbol{\alpha}, \boldsymbol{\beta}$ - angles of application of the force $P$ and of the entraining-pressing sector, respectively;

$\mathbf{l}_{\mathbf{p}}, \mathbf{I}$ - the lengths of boom applying force $P$ and of the entraining-pressing sector, respectively.

According to the literature [3], the values of the boom coefficient are within the limit $¥=0.12 \div 0.67$, then the moment of torsion will be:

$$
M_{t}=p \cdot m \cdot b \cdot R \cdot \Delta h
$$

In this case, the power consumed for carrying out the process of the green mass entraining and processing will be:

$$
N=M t \cdot \omega=p \cdot m \cdot b \cdot R \cdot \Delta h \cdot \omega
$$

\subsection{The kinematic scheme of the three-roller press for the production of sorghum juice will be shown in Figure 3}
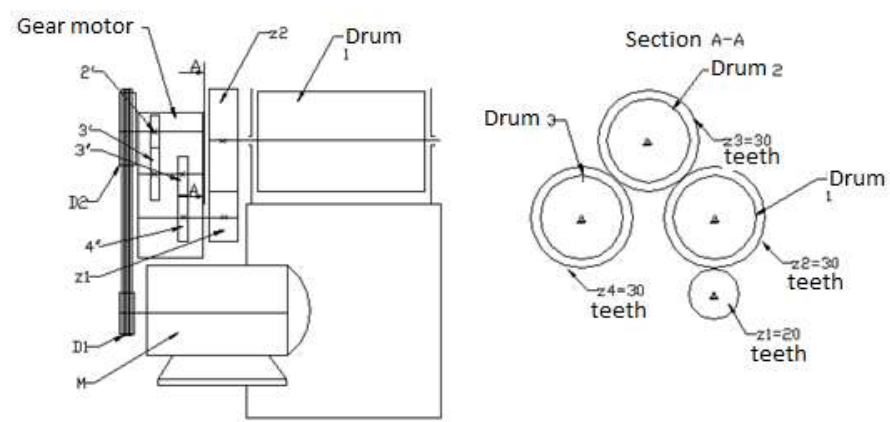

Fig.3. Kinematic scheme of the three-roller press.

Calculation of kinematic chain.

Gear ratio between belt pulleys:

$\underline{\text { Gear ratio }}$ to the reducer:

$$
i_{R C 1, R C 2}=\frac{\omega_{1 R}}{\omega_{2 R}}=\frac{D_{2}}{D_{1}}, \omega_{2 R}=\omega_{1 R} \frac{D_{2}}{D_{1}}
$$

$$
\begin{gathered}
i_{2^{\prime} 4^{\prime}}=i_{2^{\prime} 3^{\prime}} \cdot i_{3^{\prime \prime} 4^{\prime}}=\frac{\omega_{2^{\prime}}}{\omega_{3^{\prime}}} \cdot \frac{\omega_{3^{\prime \prime}}}{\omega_{4^{\prime}}}=\frac{\omega_{2^{\prime}}}{\omega_{4^{\prime}}}=\left(-\frac{z_{3^{\prime}}}{z_{2^{\prime}}}\right) \cdot\left(-\frac{z_{4^{\prime}}}{z_{3^{\prime \prime}}}\right)=\left(\frac{z_{3^{\prime}} z_{4^{\prime}}}{z_{2^{\prime}} z_{3^{\prime \prime}}}\right) \\
i_{2^{\prime} 4^{\prime}}=\frac{\omega_{2^{\prime}}}{\omega_{4^{\prime}}}=\frac{z_{3^{\prime}} z_{4^{\prime}}}{z_{2^{\prime} z_{3^{\prime \prime}}}} \\
\omega_{4^{\prime}}=\omega_{2^{\prime}}=\frac{z_{2^{\prime}} z_{3^{\prime \prime}}}{z_{3^{\prime} z_{4^{\prime}}}} ; \quad\left(\omega_{2^{\prime}}=\omega_{2 R}\right)
\end{gathered}
$$

Gear ratioto drum 1:

Gear ratio between drums 1 and 2:

$$
i_{12}=\frac{\omega_{1}}{\omega_{2}}=-\frac{z_{2}}{z_{1}}, \omega_{2}=-\omega_{1} \frac{z_{1}}{z_{2}},\left(\omega_{1}=\omega_{4^{\prime}}\right)
$$




$$
i_{23}=\frac{\omega_{2}}{\omega_{3}}=-\frac{z_{3}}{z_{2}}, \omega_{3}=-\omega_{2} \frac{z_{2}}{z_{3}}, \operatorname{or}\left(\omega_{3}=-\omega_{2}\right),\left(z_{2}=z_{3}\right)
$$

Gear ratio between drums 2 and 3:

Notations:

$$
i_{34}=\frac{\omega_{3}}{\omega_{4}}=-\frac{z_{4}}{z_{3}}, \omega_{4}=-\omega_{3} \frac{z_{3}}{z_{4}}, \operatorname{or}\left(\omega_{4}=-\omega_{3}\right),\left(\omega_{4}=\omega_{2}\right)
$$

$\omega_{1 R}-$ motor angular velocity

$$
\omega_{1 R}=\frac{\pi \cdot n_{m o t}}{30}
$$

$\omega_{I R}$ - belt pulley 2 angular velocity;

$n_{\text {mot }}$ - motor speed;

Note: $\quad$ For drum 1 we have gear 2;

For drum 2 we have gear 3 ;

For drum 3 we have gear 4.

\section{Results}

\subsection{Calculation of productivity and electric motor power to drive the three- roller press}

Using the relation (4) and replacing the set values, the volume of the material to be pressed in the unit of time results:

$$
V=400 \mathrm{~mm} \cdot 15 \mathrm{~mm} \cdot 0.150 \mathrm{~m} / \mathrm{s}=1800 \mathrm{~mm}^{3} / \mathrm{s}, \text { respectively } 3.34 \mathrm{~m}^{3} / \mathrm{h}
$$

To determine the productivity value using the relation (5), it will result:

$$
Q_{m v}=3.24 \mathrm{~m}^{3} / \mathrm{h} \times 600 \mathrm{~kg} / \mathrm{m}^{3}=1944 \mathrm{~kg} / \mathrm{h}
$$

Because of the uneven feeding that is made manually for this equipment, we will consider a $40 \%$ feed rate and will result in a pressing capacity of the sorghum stems of approx. $400 \ldots 500 \mathrm{~kg} /$ hour.

In order to calculate the electric motor power to drive the roller press, we will replace the numerical values in relations ( 8 and 9) and we will get:

Moment of torsion:

$$
M t=2 \cdot 15000 \mathrm{~N} \cdot 0.12=3600 \mathrm{Nm}
$$

Angular velocity:

$$
\omega=3.14 \cdot 12 / 30=1.256 \mathrm{rad} / \mathrm{s}
$$

Power consumed:

$$
N=3600 \cdot 1.256=4.520 W
$$

We will choose an electric motor with the power of $5.5 \mathrm{~kW}$.

\subsection{Calculation of kinematic chain}

For the presented case, the kinematic chain is the following:

Pressing roller $\mathrm{N}$ rotations $=1470 \mathrm{rpm} \times 160 / 450 \mathrm{~mm}(\mathrm{D} 1 / \mathrm{D} 2$ belt transmission $) \times 1 / 18$ (Gear ratio of parallel shaft reducer) x 20/30 (Z1/Z2-gear ratio with cylindrical gears) x 30 x $30($ Z3/Z4-gear ratio between each pair of drums $)=19.358 \mathrm{rpm}$. 


\subsection{Making diagrams for the variation of some working parameters when pressing sweet sorghum}

\section{Reference values:}

- rollers width, $\mathrm{m}$.

-material layer height,

-angular velocity, $\mathrm{rad} / \mathrm{s}$.

$$
\begin{aligned}
& \mathrm{B}_{0}=0.4 ; \mathrm{r}_{0.12} \\
& \mathrm{~m}=0.15 \\
& \omega_{0}=1.256
\end{aligned}
$$

\section{Mathematical relations used:}

Flow rate of processed material:

$$
P(F s, r, n, \omega):=\operatorname{Mt}\left(F_{s}, r, n\right) \cdot \omega
$$

Pressing drum radius, m:

$$
Q(b, h, w, r):=b \cdot h \cdot v(\omega, r)
$$

Working capacity:

$$
C(b, h, \omega, r, \rho):=Q(b, h, \omega, r) \cdot \rho
$$

Moment of torsion, $\mathrm{Nm}$ :

Power consumed by the motor, W:

$$
M t(F s, r, n):=n \cdot F s \cdot r
$$

After the application of the mathematical relations for the numerical values set in the design theme we obtained the following diagrams.

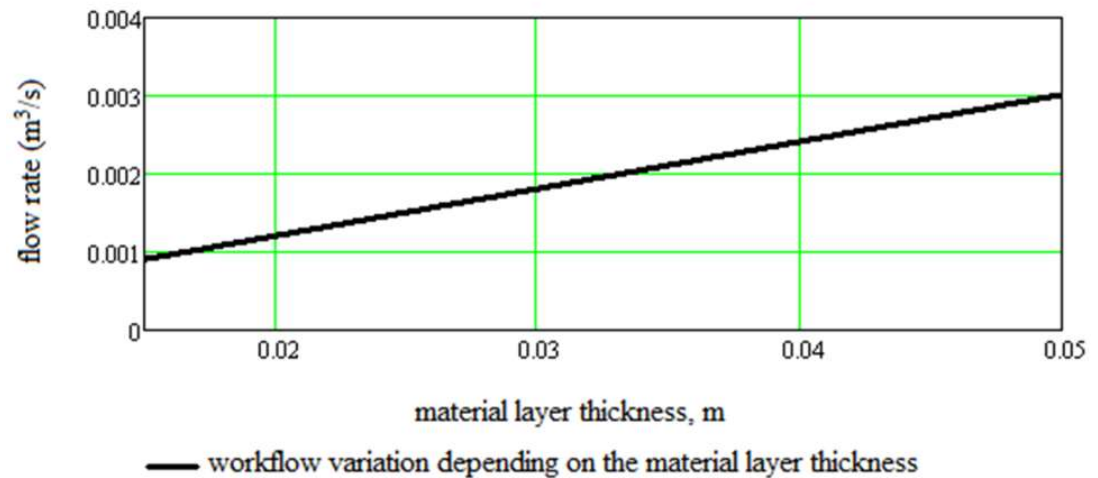

Fig. 4. Workflow variation depending on the material layer thickness, for the reference values of the model

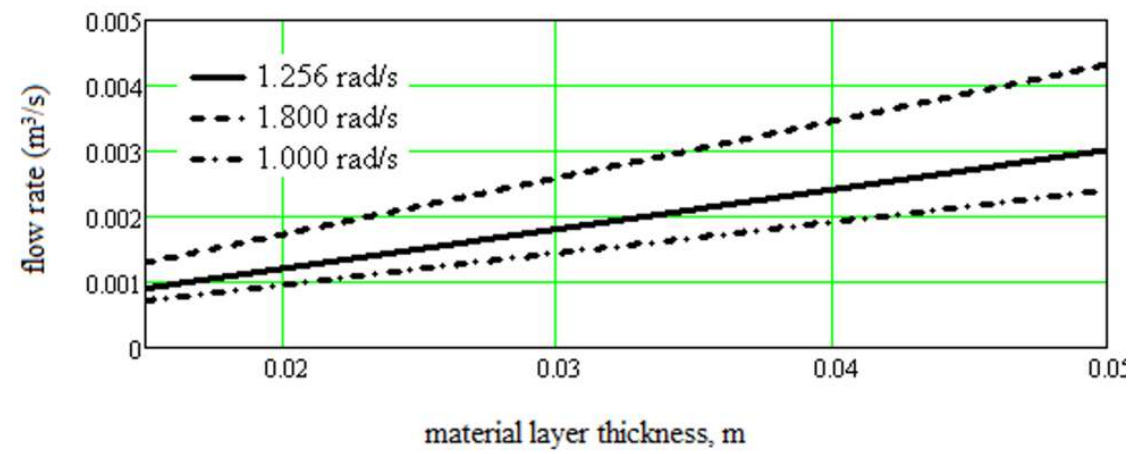

Fig. 5. Workflow variation depending on the material layer thickness, for three values of the drum's angular velocity 5 


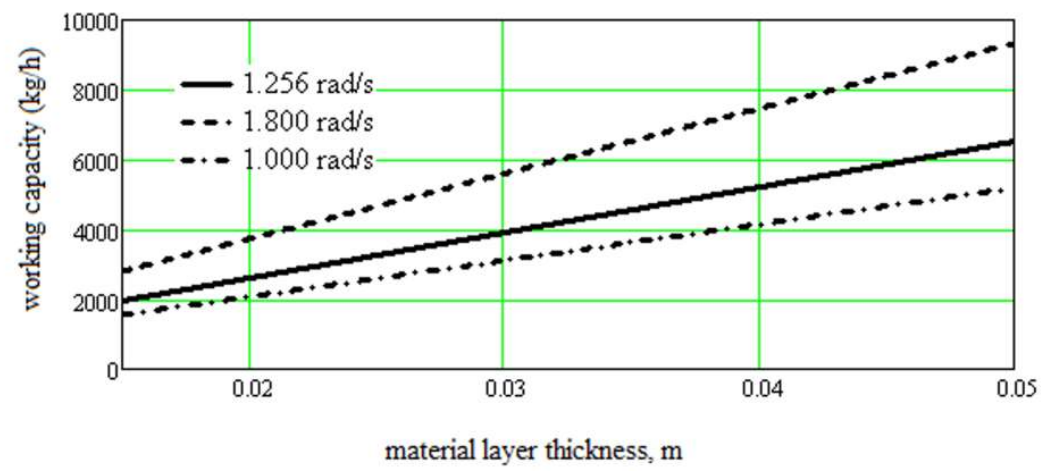

Fig. 6. Working capacity variation depending on the material layer thickness, for three values of the drum's angular velocity

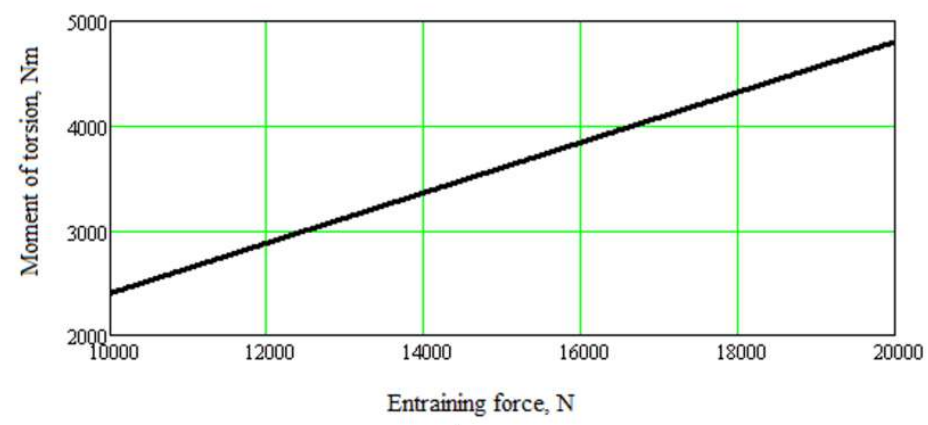

Fig. 7. Variation of the moment of torsion depending on the entraining force.

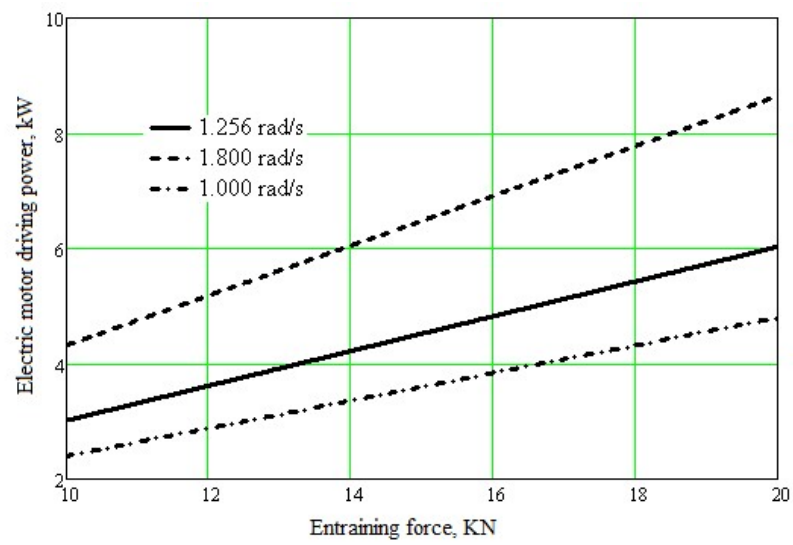

Fig. 8. Variation of electric motor power depending on the entraining force. 


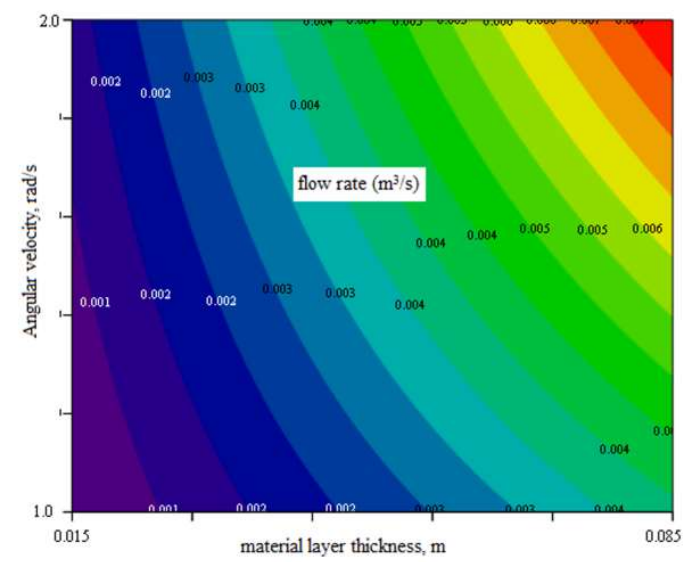

Fig. 9. Variation of the material flow rate depending on material layer thickness and angular velocity on the isocline map.
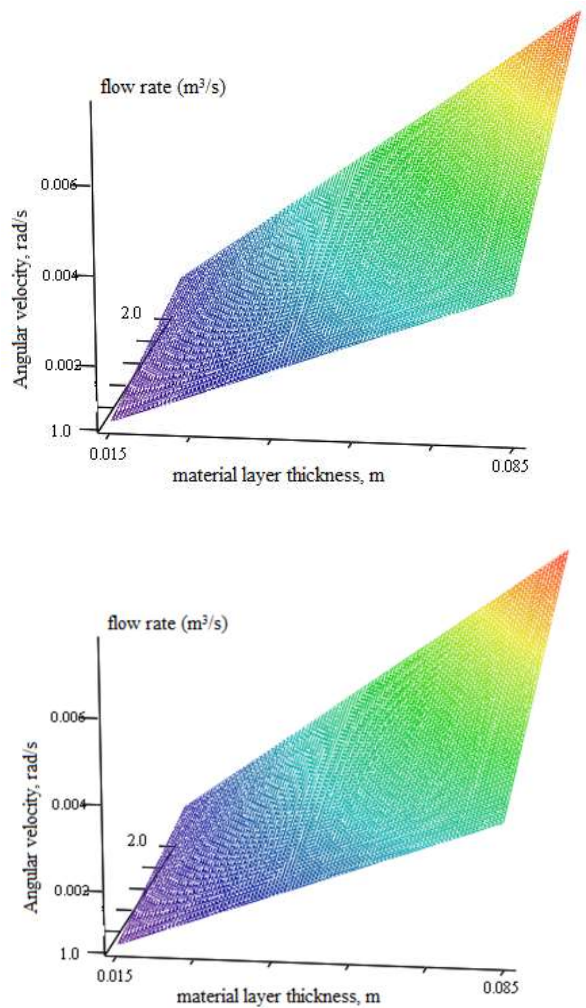

Fig. 10. Variation of the material flow rate depending on material layer thickness and angular velocityby surface representation.

The analysis of the study carried out establishes the following theme of constructive design for a functional prototype to be used in the research project:

Three-roller press, belt transmission and parallel shaft reducer drive, electric motor power $5.5 \mathrm{~kW}$, drum diameter $240 \mathrm{~mm}$, drum length $400 \mathrm{~mm}$, pressing capacity 400-500 $\mathrm{kg} /$ hour, determined by gearmotor and roller length but also by the uniformity of manual feed. (Olan M. et al 2018). 


\subsection{Realization of the three-roller press construction project}

The three-roller press (Figure 11) is intended for pressing sorghum stems to obtain the juice to be used for the production of bioethanol. $[1,10]$

The installation for pressing sorghum stems is composed of a support (1) on which is mounted a pressing unit $(2)$ with three rollers $(3,4,5)$ which are driven together by two gears $(6 ; 7$ and $8 ; 9)$ and the rotation movement is received by means of a pinion (10) from a parallel shaft reducer (11), a belt pulley transmission and some trapezoidal belts which take up the rotation movement from an electric motor (12) and transmits it to that parallel shaft reducer (11).

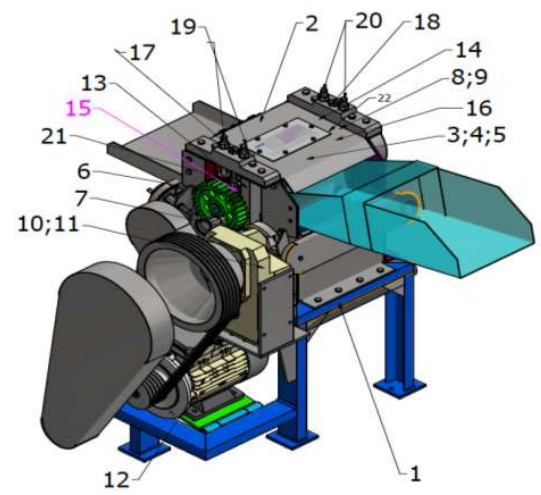

Fig. 11. Press for sorghum stems.

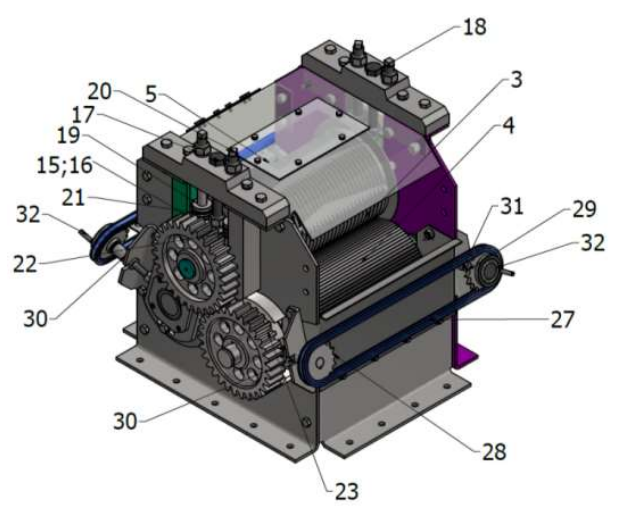

Fig.12. Three-roller pressing unit.

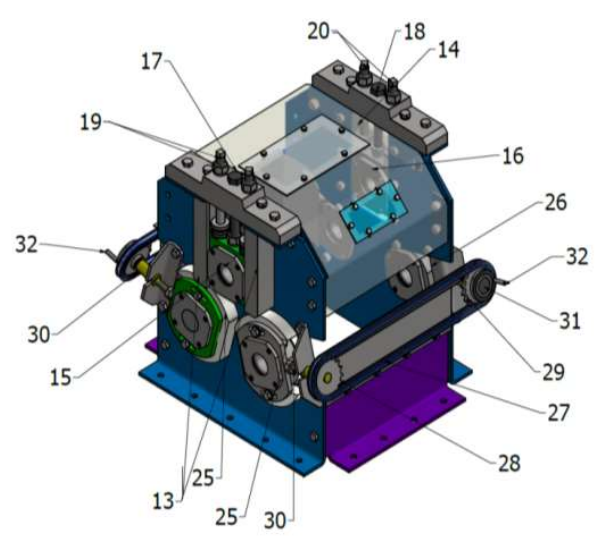

Fig.13. Housing construction and rollers adjusting mechanisms

The pressing unit has two vertical guides $(13 ; 14)$ on which a pressing roller $(3)$ slides having on the work surface some special profiles for entraining the sorghum stems and circular channels with a triangular section for pressing the sorghum. The two bearings (15; 16) supporting the pressing roller (3) are vertically adjusted with a hexagonal screw (17; $18)$ and two threaded rods $(19 ; 20)$ on which some sets of disc springs are mounted $(21 ; 22)$ which maintain an elastic pressure during the working process by directly pressing on some bearings supporting this pressing drum. [3; 5]

Under the pressing roller there are mounted two working rollers $(4 ; 5)$ having special profiles on axial and circular ( $\mathrm{R}$ and $\mathrm{T})$ direction to the working surface, which aim 
to increase the entraining capacity of the sorghum stems and also the final pressing on two working directions which will increase the degree of juice squeezing from the sorghum stems. The two working rollers are moved by means of bearings $(23 ; 24)$ and of mechanisms on two special guides $(25 ; 26)$ to increase or decrease the distance between each of these rollers and the upper pressing roller (3).

For the identical movement of the two bearings supporting each of the two working rollers $(4: 5)$, the installation is provided with a Gall chain transmission (27) and two pinions $(28 ; 29)$ mounted on the threaded rods $(30 ; 31)$ which move the bearings $(23$; 24) on each end of the working rollers $(4 ; 5)$ and which is actuated by one handwheel (32) for each transmission from the two working rollers. For fine adjustment, each of the two threaded rods $(30,31)$ has a graduated drum. [1]

The juice obtained after sorghum pressing operation is collected in a vessel placed at the bottom of the installation and then transported to a tank. [5]

To increase adherence to stems entrainment, a technical solution is the progressive increase by $1-2 \%(2.5-5 \mathrm{~mm})$ of the three rollers diameters in the following order: roller 2 ; roller 1 and roller 3 according to Figure 14.

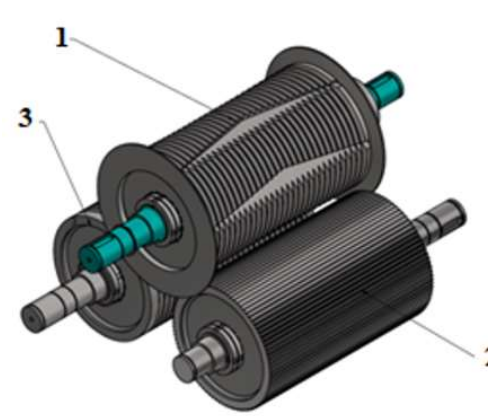

Fig.14. Constructive form of pressing rollers.
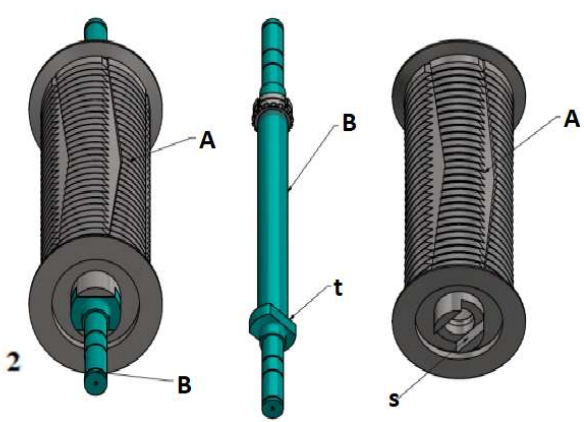

Fig.15. Dismountable roller construction.

Another technical solution for reducing friction and increasing the degree of stem entrainment, the three rollers will have different shapes according to Figure 6.

Thus:

- roller 1 will have channels with a triangular profile on a radial direction to the axis of rotation and for the purpose of entraining are made 4-6 special millings, of triangular shape, which will form stem entraining teeth; [3].

- roller 2 will have channels with a triangular profile on an axial direction to the axis of rotation but perpendicular to the direction of roller 1 channels, obtaining both the entrainment of stems and their primary pressing;

- roller 3 will have channels with a profile similar to roller 1 but displaced by half a step to allow tooth full on empty pressing between rollers 1 and 3 but also pressing in a direction perpendicular to the pressing between the rollers 1 and 2 , thus obtaining a rectangular network for pressing the stems and extracting the juice, which will increase the extraction rate. [2]

To save materials and workmanship and for safety in operation in case of wear, the three rollers (1,2 and 3) are executed in the version with a removable shaft. [1]

\section{Conclusions}

In this article, the main constructive data underlying the design of three-roller presses for the production of sweet sorghum juice necessary for bioethanol production have been presented and analyzed. The influence of the main parameters on the power consumed 
has also been analyzed. Having available the studies on the analyzed constructive solutions and the computational elements necessary for this type of installations, the constructive project of the prototype installation for sorghum pressing was prepared, the prototype variant Figures 11;12 and 13 with the following technical characteristics:

Three-roller press for sweet sorghum, belt transmission and parallel shaft reducer drive, electric motor power $5.5 \mathrm{~kW}$, drum diameter $240 \mathrm{~mm}$, drum length $400 \mathrm{~mm}$, pressing capacity $400-500 \mathrm{~kg} /$ hour, determined by gearmotor and roller length but also by the uniformity of manual feed.

\section{Acknowledgement}

This work was supported by a grant of the Romanian Research and Innovation Ministry, through Programme 1 - Development of the national research-development system, sub-programme 1.2 Institutional performance - Projects for financing excellence in RDI, contract no. 16 PFE.

\section{References}

1. V. Jinga, V. Vlăduț, E. Marin, D. Manole, Cultura de sorg o soluție pentru agricultura dobrogeană, ISB-INMA TEH' 2018, 951-954 (2018).

2. J. Fei, J. Chawhuaymak, R. Mark, Z. Werner, and K. L. Ogden, Efficient extraction method to collect sugar from sweet sorghum, Journal of Biological Engineering, 7, (2013).

3. I. Caba, E. Laza,V. Vlăduț, E. Marin, N.Ungureanu, S. Biriş, I. Găgeanu, I. Voicea, S. Isticioaia, M. Olan, Gh. Matei, Sweet sorghum - an alternative for Romanian farmers in the conditions of the current climate change, ISB-INMA TEH' 2018, 961-970, (2018).

4. V. Cerempei, I. Habasescu, Technical solutions for the production of liquid biofuels, Institute of agricultural technique "MECAGRO", (INNOVATIVE TECHNOLOGIES, Republic of Moldova, 2014).

5. I. Dumitru, D.E. Iuga, M. Cristea, A.I. Grigore, L. Vladuțoiu, Gh Stroescu., M.R. Oprescu, V. Vlăduţ, I. Voicea, L-D. Popa, S. Boruz, F.D. Sîrbu, Considerations on energetic crops potential, $47^{\text {th }}$ CONFERENCE OF ESNA, 48, 257-264, (2018).

6. R. Oprescu, I. Voicea, V. Vlăduț, I. Găgeanu, D. Cujbescu, C. Persu, D. Iuga, S.Şt. Biriş, I. Dumitru, Gh. Stroescu, L-D. Popa, S. Boruz, Considerations on the extraction technology of sugar sorghum juice, $47^{\text {th }}$ CONFERENCE OF ESNA, 48, 367-374, (2018).

7. A.I. Grigore, I. Grigore, L. Cristea, M. Cristea, L. Vlăduţoiu, I. Voicea, V. Vlăduţ, M. Epure, P. Andrei, C. Popescu, S. Boruz, Gh. Matei, Considerations on the importance of cultivating sorghum to the biofuel industry for producing bioethanol, $47^{\text {th }}$ CONFERENCE OF ESNA, 48, 283-288, (2018).

8. M. Olan, V. Vlăduț, A. Păun, A. Vișan, P. Găgeanu, I.Voicea, I. Găgeanu, Analysis of technique current stage in the field of sorghum pressing equipment designed to produce the raw juice necessary to obtain the bioethanol, ISB-INMA TEH' 2018, 221228, (2018),

9. V Vlăduţ., S. Bungescu, The fondation of the technology for mechanizing the saccharate sorghum crop and specific et optimizing solution, $\mathrm{V}^{\text {th }}$ International Symposium "YOUNG PEOPLE AND MULTIDISCIPLINARY RESEARCH", Sect B - Biotechnology, Agriculture, Veterinary Medicine, 369-381, (2003).

10. Gh. Matei, V. Vlăduț, M. Vladu, R.L. Pânzaru, P. Săvescu, C. Sălceanu - Study on the influence of mineral fertilization on the biomass yield of sweet sorghum cultivated in the Caracal plain, ISB-INMA TEH' 2018, 1021-1026, (2018). 